Historic, Archive Document

Do not assume content reflects current scientific knowledge, policies, or practices. 


\section{WARD AVOCADO TREES}

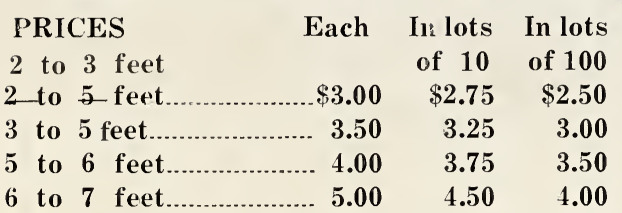

The WARD AVOCADO bears while young. In all cases where WARD buds have been inserted in a tree with other varieties, such as Fuerte, Dickinson, etc., at the same time, the WARD buds have borne at least a year before the other varieties.

Nine months after blossoming the WARD AVOCADO is ready to pick. This is an important point, for in ripening so shortly after blooming, the liability to damage from wind and frost is greatly reduced.

The tree is a vigorous grower and upright in habit. Buds unite readily and grow out quickly. The foliage is the handsomest of any named variety we have seen, being extra wide and long, with a bright reddish pink new growth.

The WARD AVOCADO is a natural hybrid from Guatemalian and Mexican parentage. It has the hardy characteristics of the Mexican varieties with the finer qualities of the Guatemalian, combined. The flavor and quality are unexcelled.

The parent WARD AVOCADO tree went through the freeze of 1921 showing almost no damage to either fruit or foliage while other varieties all about it were frozen back very severely.

The fruit weighs 12 to 20 ounces. The color is a rich dark purple with light brown spots.

The skin is slightly rough and 1-32 to 1-16 inch thick. It is thick enough to ship well but not hard and woody.

Oil content is 24.89 per cent, which is much higher than the average avocado.

The seed of the WARD AVOCADO is comparatively small, weighing $13 \frac{1}{4}$ oz. in a one-pound fruit, and is tight in the cavity.

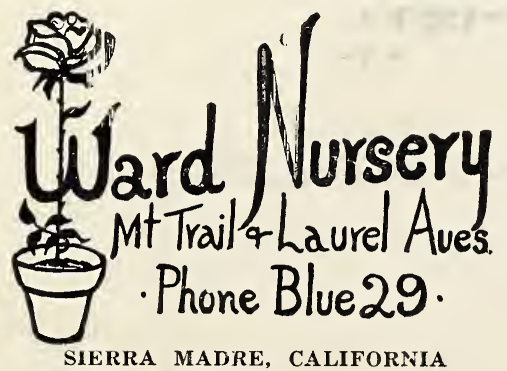




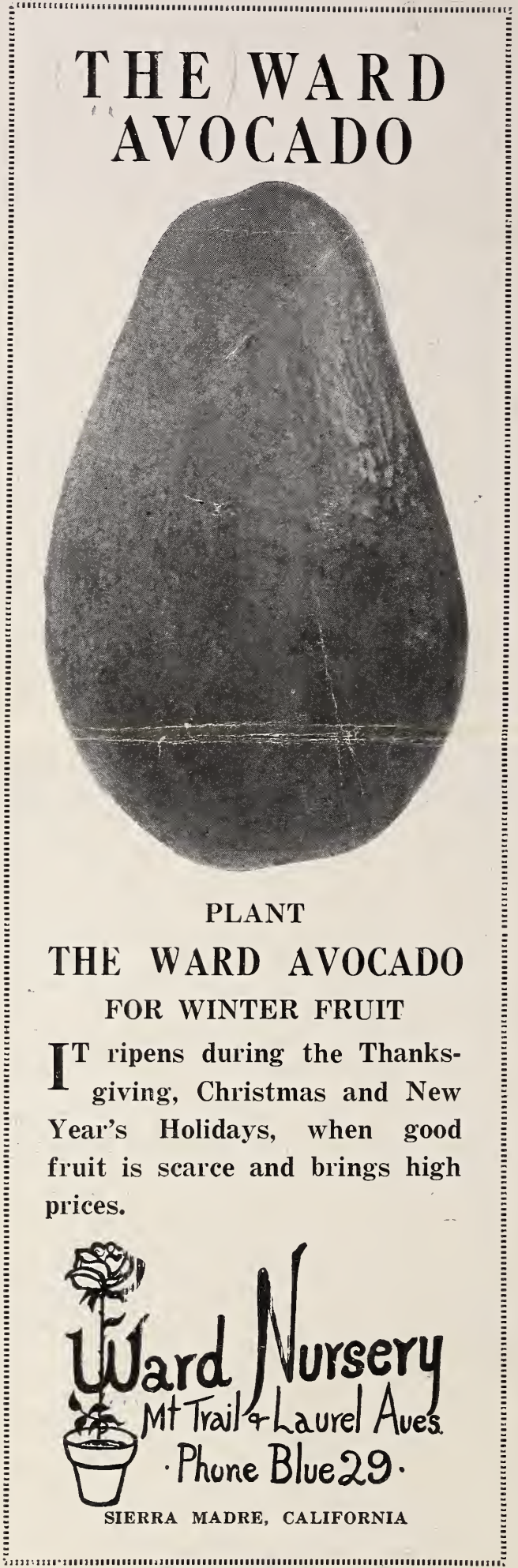

